\title{
Editorial to additional papers
}

\section{Paolo Carbone}

University of Perugia, Italy

Section: EDITORIAL

Citation: Paolo Carbone, Editorial to additional papers, Acta IMEKO, vol. 6, no. 2, article 14, July 2017, identifier: IMEKO-ACTA-06 (2017)-02-14

Section Editor: Paul Regtien, Measurement Science Consultancy, The Netherlands

Received July 14, 2017; In final form July 14, 2017; Published July 2017

Copyright: (C) 2017 IMEKO. This is an open-access article distributed under the terms of the Creative Commons Attribution 3.0 License, which permits unrestricted use, distribution, and reproduction in any medium, provided the original author and source are credited

Corresponding author: Paolo Carbone, email: paolo.carbone@unipg.it

Dear Reader,

three additional papers are closing this issue.

The first one covers the interesting area of human computer interaction. It is entitled 'A preliminary approach to study the behaviour of human fingertip at contact via experimental test and numerical model' and it is authored by Maria Laura D'Angelo et al. The paper describes the measurement results associated with the deformation of the fingertips, as a function of the exercised force on a flat surface. It includes information on the contact area and of the fingertip pressure contour. Both theoretical and experimental results are described.

The next paper, authored by Valeriy Didenko, is entitled 'Improved evaluation of uncertainty for indirect measurement'. It covers the subject of uncertainty evaluation in indirect measurements and presents the analysis of several practical cases, occurring when using multi-channel ADC-based acquisition and measurement systems.

The last paper in this issue is authored by Natsue Yoshimura et al. It is entitled 'Decoding of emotional responses to userunfriendly computer interfaces via electroencephalography signals'. It contains a statistical analysis of emotional responses of users of unfriendly computer interfaces. The analysis is supported by electroencephalography derived data, performed by stressing users in target-reaching tasks.

Have a fruitful reading of this second issue of ACTA IMEKO in 2017 !

Paolo Carbone, Editor-in-Chief of ACTA Imeko. 